\title{
Regulation of the Sox3 Gene in an X0/XO Mammal without Sry, the Amami Spiny Rat, Tokudaia osimensis
}

\author{
Kohei Washio $^{a} \quad$ Shusei Mizushima ${ }^{a, b}$ Takamichi Jogaharac, d Asato Kuroiwa ${ }^{a, b}$ \\ ${ }^{a}$ Reproductive and Development Sciences, Biosystems Science Course, Graduate School of Life Science, \\ Hokkaido University, Sapporo, Japan; ${ }^{b}$ Division of Reproductive and Developmental Biology, Department of \\ Biological Sciences, Faculty of Science, Hokkaido University, Sapporo, Japan; ' Division of Bio-Resources, \\ Frontier Science Research Center, Kiyotake Campus, University of Miyazaki, Kiyotake-cho, Japan; ${ }^{\text {FFaculty of }}$ \\ Law and Economics, Okinawa University, Naha, Japan
}

\section{Keywords}

Evolution - Sex chromosomes - Sex determination - Sox3 .

Tokudaia $\cdot \mathrm{X} 0 / \mathrm{X} 0$ system $\cdot \mathrm{Y}$ chromosome

\begin{abstract}
Two species of spiny rats, Tokudaia osimensis and Tokudaia tokunoshimensis, show an X0/X0 sex chromosome constitution due to the lack of a $Y$ chromosome. The Sry gene has been completely lost from the genome of these species. We hypothesized that Sox3, which is thought to be originally a homologue of Sry, could function in sex determination in these animals in the absence of Sry. Sox 3 was localized in a region of the $\mathrm{X}$ chromosome in $T$. osimensis homologous to mouse. A similar testis- and ovary-specific pattern of expression was observed in mouse and T. osimensis. Although the sequence of the Sox 3 gene and its promoter are highly conserved, a 13-bp deletion was specifically found in the promoter region of the 2 spiny rat species. Reporter gene assays were performed to examine the effect of the 13-bp deletion in the promoter region on Sox 3 regulation. Although an approximately $60 \%$ decrease in activity was observed using the Tokudaia promoters with the 13-bp deletion, the activity was recovered using a mutated promoter in which the deletion was filled with mouse sequence. To evaluate whether SOX3 could regulate Sox9 expression, a reporter gene assay was
\end{abstract}

carried out using testis-specific enhancer of Sox9 core (TESCO). Co-transfection with a combination of mouse SF1 and mouse SOX 3 or T. osimensis SOX 3 resulted in a greater than 2 -fold increase in activity of mouse and T. osimensis TESCO. These results support the idea that the function of SOX3 as a transcription factor, as has been reported in mice and humans, is conserved in T. osimensis. Therefore, we conclude that the Sox3 gene has no function in sex determination in Sry-lacking Tokudaia species.

(c) 2019 S. Karger AG, Basel

Sex-determining region Y (SRY)-box genes are a large family of genes encoding a group of proteins that carry a DNA-binding high mobility group (HMG) domain and additional domains involved in transcriptional regulation [reviewed in Pevny and Lovell-Badge, 1997; Wegner, 1999]. This domain was first identified in $S r y / S R Y$, a sexdetermining gene on the $\mathrm{Y}$ chromosome of eutherian mammals [Gubbay et al., 1990; Sinclair et al., 1990]. Together with nuclear receptor subfamily 5 , group A, member 1 (NR5A1, also referred to as SF1), SRY binds directly to the enhancer and synergistically upregulates the expression of Sox9 (SRY-box 9) [Sekido and Lovell-Badge, 2008; Gonen et al., 2018]. After SOX9 expression reaches a threshold, SOX9 maintains its own expression via its

\section{KARGER}

(c) 2019 S. Karger AG, Basel

E-Mail karger@karger.com

www.karger.com/cgr
Asato Kuroiwa

Division of Reproductive and Developmental Biology

Department of Biological Sciences, Faculty of Science

Hokkaido University, Kita-10, Nishi-8, Kita-ku, Sapporo 060-0810 (Japan)

E-Mail asatok@ sci.hokudai.ac.jp 
enhancer. SOX9 mainly functions in testis differentiation in vertebrates. Specifically, in eutherians, SOX9 is involved in the differentiation of the precursor cells to Sertoli cells in the gonads of XY embryos after sex determination by SRY. SOX9 directly regulates the expression of anti-müllerian hormone (AMH, also known as müllerian inhibitory substance, MIS). After initiation of testes differentiation, $A M H$ expression is induced in the Sertoli cells of eutherian mammals [Vigier et al., 1983; Josso and Picard, 1986; Josso et al., 1993].

SOX genes are expressed in various phases of embryonic development and cell differentiation in a manner linked to cell speciation. They perform their functions as part of a complex interplay with other transcription factors, highly dependent on cell type and promoter context [reviewed in Kamachi et al., 2000]. SOX3 (SRY-box 3) is a single-exon gene located on the $\mathrm{X}$ chromosome [Stevanović et al., 1993; Collignon et al., 1996]. This gene is widely expressed in the central nervous systems of vertebrate embryos and is required for normal brain development. By contrast, its expression is extremely low or absent in the developing gonads of mice and marsupials [Collignon et al., 1996; Pask et al., 2000]. Thus, although SOX3 does not normally function in sex determination, an evolutionary link between SOX3 and SRY is indicated. Of the 20 SOX genes in the mammalian genome, $S O X 3$ encodes a protein that is most similar to SRY, sharing 67\% amino acid identity (and 90\% similarity) across the HMG-domain [Stevanović et al., 1993; Bowles et al., 2000]. From molecular and cytogenetic studies of $\mathrm{X}$ and $\mathrm{Y}$ chromosomes, it was hypothesized that SRY and SOX3 originally were homologs and SRY evolved from SOX3 due to a gain-of-function mutation in the lineage of therian mammals [Foster and Graves, 1994; Graves, 2006]. Transgenic mice overexpressing SOX3 showed its ectopic expression in the bipotential gonads, frequently leading to complete XX male sex reversal [Sutton et al., 2011]. This suggests that the 2 SOX genes are functionally interchangeable in sex determination.

All 3 species of the genus Tokudaia (Muridae, Rodentia) have uniquely evolved in their sex chromosomes and sex-determining mechanisms. The Okinawa spiny rat (Tokudaia muenninki) has an XX/XY sex chromosome constitution as mammals generally have. However, the neo-X and neo- $\mathrm{Y}$ chromosome regions were acquired by fusion of a pair of autosomes to $\mathrm{X}$ and $\mathrm{Y}$ chromosomes in T. muenninki [Murata et al., 2012]. Two species of Tokudaia, the Amami spiny rat (T. osimensis) and the Tokunoshima spiny rat (T. tokunoshimensis), show an $\mathrm{X} 0 / \mathrm{X} 0$ sex chromosome constitution due to lack of the Y chromosome [Honda et al., 1977, 1978; Kobayashi et al., 2007].
Several Y-linked genes have been rescued by translocation or transposition to the $\mathrm{X}$ chromosome and/or autosomes [Kuroiwa et al., 2010]. However, Sry has been completely lost from the genome of these species [Sutou et al., 2001; Murata et al., 2010], suggesting that they have acquired a new sex-determining mechanism that functions independent of SRY. SOX9 is also important for the sexual differentiation of this species [Kimura et al., 2014]. Furthermore, Amh expression is regulated by SOX9 in T. osimensis, similar to the mechanism observed in the mouse [Otake and Kuroiwa, 2016]. These previous studies indicate that a new sex-determining gene that superseded Sry regulates the Sox 9 expression in these species, but this putative gene has not yet been identified.

In this study, we investigated the possibility that SOX3 could perform the role of SRY in sex determination in Sry-lacking Tokudaia species. The coding sequence of the Sox3 gene was highly conserved in Tokudaia species, but a 13-bp deletion was found in the promoter sequence. We were unable to determine the expression of Sox 3 in the embryonic gonads of Tokudaia because all species are endangered and protected by the Japanese government [Yamada et al., 2010]. Furthermore, experimental samples of embryonic gonads from Tokudaia species are currently not available. Therefore, we analyzed the expression pattern of Sox3 in adult animals and performed an in vitro reporter gene assay to examine the effect of the 13-bp deletion on Sox3 regulation.

\section{Materials and Methods}

\section{Animals}

All 3 species of Tokudaia (T. muenninki, T. osimensis, T. tokunoshimensis) are endangered (IUCN Red List of Threatened Species, https://www.iucnredlist.org/), and have been protected by the Japanese government as a natural monument since 1972. With permission from the Agency for Cultural Affairs and the Ministry of the Environment in Japan, all animals were released at their capture sites after a small piece was cut from the tip of their tail. Tissues were harvested from animals that died naturally or accidentally. DNA was extracted from the tail tissues as reported previously [Kuroiwa et al., 2011]. Slc:ICR strain mice were used for obtaining the coding sequence (CDS) of Sox3 and its promoter as a control.

Screening of the BAC Clone and Cloning and Sequencing of the Sox3 Gene and Promoter

A BAC library derived from a single male T. osimensis was constructed previously [Kimura et al., 2014]. The BAC library was screened using a 2-step 3-dimensional PCR screening system, as described [Kimura et al., 2014]. The primer sequences used are shown in Table 1. The experimental number of the isolated BAC clone is TOB1-256I18. CDS and promoter sequence of T. osimen- 
Table 1. Primer list

\begin{tabular}{|c|c|c|}
\hline Experiment & Forward primer, $5^{\prime} \rightarrow 3^{\prime}$ & Reverse primer, $5^{\prime} \rightarrow 3^{\prime}$ \\
\hline Screening of BAC clone & TGA AAA CGG ATT TTC CAA GG & CCT TCA CTT TYT CGC TCT GG \\
\hline \multicolumn{3}{|l|}{ Cloning } \\
\hline CDS of Sox3 & ATG CGA CCA GCT CGA GAG A & TCA GAT GTG GGT CAG CGG \\
\hline Sox3 promoter & TGA AAA CGG ATT TTC CAA GG & GTA AAG GCC GGG GGA CTC \\
\hline \multicolumn{3}{|l|}{ RT-PCR } \\
\hline Sox3 & GCC TTG CTG TTT AGC TTT GC & CSG GAC TTC TYG CTT TTG TA \\
\hline Actb & AAG GCC AAC GCN GAR AAG ATG & TGC GCA AGT TAG GTT TTG TCA AA \\
\hline \multicolumn{3}{|l|}{ Reporter gene assay } \\
\hline SOX3 expression vector & GCA AGC TGC GAA TGC GA & TCA GAT GTG GGT CAG CGG \\
\hline Sox3 promoter of mouse & CCG AGC TCC CAG GTG GGC CAT GGG ATG GGG CG & CCA AGC TTG GCT TCT CTC ACC TGA TGC GTT \\
\hline Sox3 promoter of Tokudaia & CCG AGC TCC CAG GCC GGC CAC GGG ATG GGG CG & CCA AGC TTG GCT TCT CTC ACC TGA TGC GTT \\
\hline \multirow[t]{2}{*}{ Overlap extension PCR } & TGA AAA CGG ATT TTC CAA GG & CGC AGC TTG CCC GGG AAG CTT GCC CGG CCT \\
\hline & AGC TTC CCG GGC AAG CTG CAA TGC GCG AC & GTA AAG GCC GGG GGA CTC \\
\hline
\end{tabular}

sis Sox3 were determined by sequencing of the BAC clone. The Sox 3 promoter region in T. osimensis female, T. tokunoshimensis male and female, and T. muenninki male and female was amplified by PCR using genomic DNA as a template, and the sequence was determined.

Total RNA was extracted from mouse and T. osimensis tissues using the RNeasy Mini Kit (Qiagen, Hilden, Germany) according to the manufacturer's instructions. The total RNA was reverse transcribed using SuperScript III (Invitrogen) and oligo(dT) primers. The synthesized cDNA was used as a template for CDS amplification. A primer pair was designed to amplify the CDS (Table 1). The GenBank accession numbers are as follows: LC431772 for Sox3 CDS in T. osimensis, LC431773 for the Sox3 promoter in T. osimensis, and LC431774 for the Sox3 promoter in T. tokunoshimensis.

\section{Preparation of Chromosomes and FISH Mapping of the BAC} Clone

Preparation of R-banded chromosomes and direct R-banding FISH analyses were performed as described previously [Kobayashi et al., 2007; Kimura et al., 2014]. The BAC clone containing Sox3 was used as a probe.

\section{Reverse Transcription-PCR}

Total RNA was extracted from liver, kidney, heart, whole brain, testis, and ovary of mouse and T. osimensis using the RNeasy Kit (Invitrogen, CA) according to the manufacturer's instructions. RNA was treated with DNase I and reverse transcribed using SuperScript III reverse transcriptase (Invitrogen) and oligo(dT) primers. The primers are listed in Table 1.

\section{Construction of Plasmids and Reporter Gene Assays}

Forward primers and reverse primers with SacI and HindIII restriction sites, respectively (Table 1), were designed to amplify the Sox3 promoter regions of mouse, T. osimensis, and T. tokunoshimensis. The PCR products were cloned into the SacI/HindIII sites of the PGL3-Basic vector (Promega, WI). A reporter construct containing the Sox 3 promoter of T. osimensis in which the 13-bp deletion was filled with the mouse sequence was generated by overlap extension PCR, as described previously [Ho et al., 1989;
Kimura et al., 2014]. The sequences of a set of complementary primers covering the filled deletion are shown in Table 1 . The reporter activity was measured using NT2/D1 cells as reported by Kovacevic Grujicic et al. [2005] and Kimura et al. [2014].

Mouse and T. osimensis Sox3 expression vectors were constructed as described previously [Kimura et al., 2014]. The primer sequences used to amplify Sox 3 of each species are shown in $\mathrm{Ta}$ ble 1 . The PCR product was cloned into the PMD20-T vector (Takara, Kusatsu, Japan). The DNA fragment digested by BamHI and $X b a I$ was cloned into the $B a m \mathrm{HI} / X b a I$ sites of the expression vector, $\mathrm{pcDNA}^{\mathrm{TM}} 3.1(+)$ (Invitrogen). Luciferase vectors containing the SV40 promoter and mouse testis-specific enhancer of Sox9, testis-specific enhancer of Sox 9 core (TESCO) or T. osimensis TES$\mathrm{CO}$, and the expression vectors containing mouse Sf1 (mSF1), mouse Sry (mSRY), or T. osimensis Sox9 (SOX9) were constructed previously [Kimura et al., 2014]. The amino acid sequences of mouse and T. osimensis SF1 are identical. The reporter activity was measured as described for COS7 cells [Kimura et al., 2014].

\section{Statistical Analysis}

The data are presented as the mean \pm SD. Statistical comparisons were performed using Tukey range tests.

\section{Results}

\section{The Sox3 Gene Is Conserved with the Exception of a} 13-bp Deletion in the Promoter Region

To determine the chromosomal location of Sox3 in T. osimensis, FISH mapping was performed. The $T$. osimensis BAC clone containing Sox3 was used as a probe. Sox3 was mapped to Xq23.2 by BAC FISH (Fig. 1). The fluorescent signal was found at a single locus in a single $\mathrm{X}$ chromosome. This locus was within a homologous region on the mouse and rat X chromosomes [Kobayashi et al., 2008; Murata et al., 2012]. 
Fig. 1. Chromosomal localization of Sox3 in Tokudaia osimensis. The BAC clone containing Sox3 was mapped to Xq23.2 in male $(\mathbf{A})$ and female (B) specimens. Arrows mark the hybridization signals. A, C Propidium iodide-stained R-banding patterns. C, D DAPI staining. Scale bar, $10 \mu \mathrm{m}$.
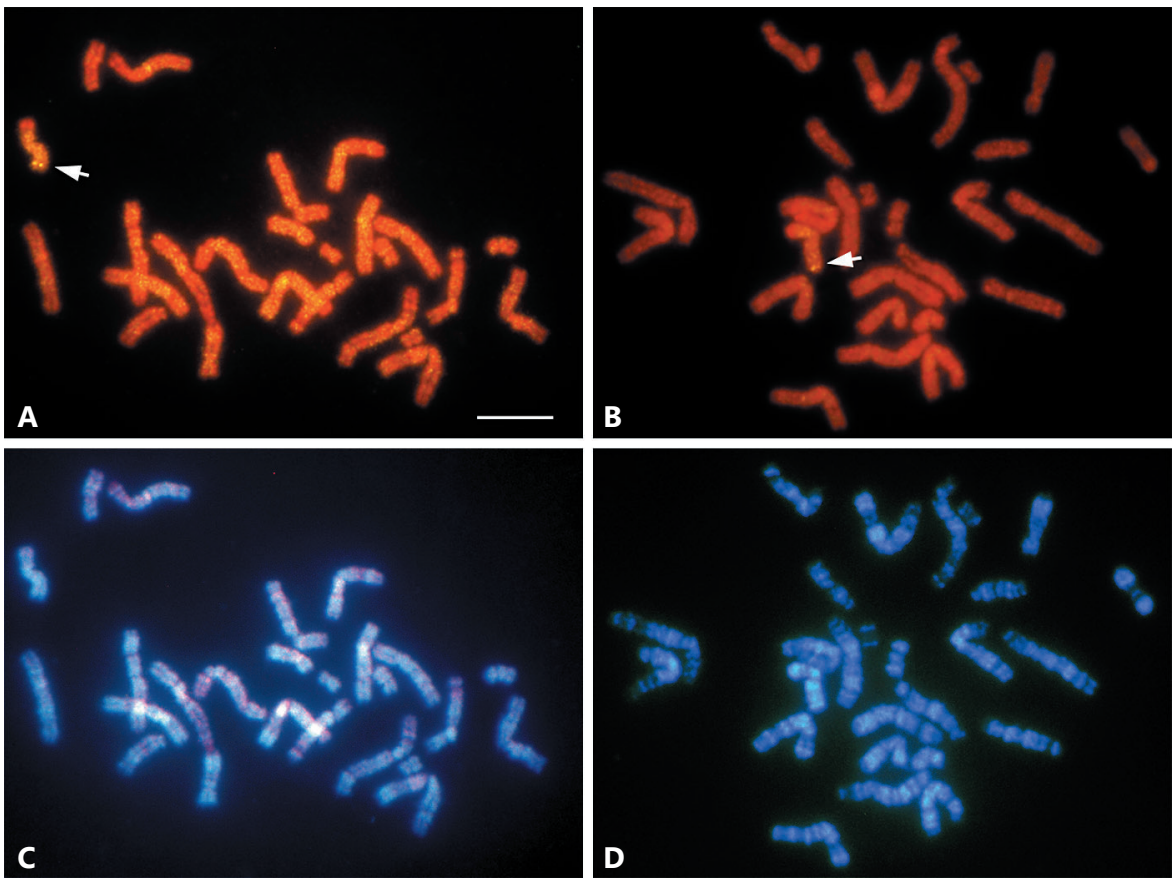

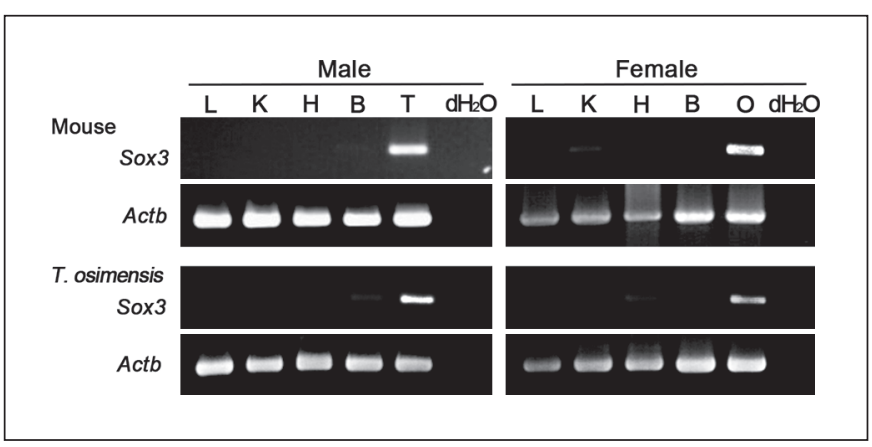

Fig. 2. Expression of Sox3 in mice and Tokudaia osimensis. The expression pattern of Sox 3 in male and female mice and T. osimensis was examined by RT-PCR. L, liver; K, kidney; $\mathrm{H}$, heart; $\mathrm{B}$, whole brain; T, testis; O, ovary. Actb was used as internal control. For the negative control, distilled water $\left(\mathrm{dH}_{2} \mathrm{O}\right)$ was used as template.

The expression of Sox3 was examined by RT-PCR (Fig. 2). A similar testis- and ovary-specific pattern of expression was observed in mouse and T. osimensis. Testisspecific expression in adult male mice was previously shown by Northern blot analysis [Collignon et al., 1996]. Based on the band density, Sox3 expression was higher in mice than in T. osimensis.

The size of the Sox3 CDS in T. osimensis was 1,356 bp. The nucleotide and amino acid sequences showed 94.8 and $95.8 \%$ identity to mouse, respectively. The
HMG-box of T. osimensis SOX3 was completely identical to that of mouse (Fig. 3A). The Sox3 promoter sequences in T. osimensis and T. tokunoshimensis were determined (Fig. 3B). Although all of the putative transcription factor-binding sites previously identified in mouse using MatInspector program [Kovacevic Grujicic et al., 2005] were conserved in the 2 Tokudaia species, a 13-bp deletion ( -1 to -13$)$ was observed in these (gray shading in Fig. 3B). The promoter sequence $(+1$ to -28$)$ of mice, rats, T. muenninki (XX/XY), T. osimensis (X0/X0), and T. tokunoshimensis (X0/X0) are shown in Figure 3C. A 13-bp deletion was only observed in the 2 X0/X0 Tokudaia species. There were no sex differences in the promoter sequences of all Tokudaia species.

\section{Decreased Expression Level Caused by a 13-bp}

Deletion in the Tokudaia Sox3 Gene

Kovacevic Grujicic et al. [2005] performed a chloramphenicol acetyltransferase reporter assay in NT2/D1 cells and reported that the region spanning -219 to +67 bp of the human SOX3 gene was the core promoter region, and positive cis-regulatory elements were located within the region -427 to -219 bp. Therefore, we examined Sox 3 promoter activity using constructs containing the regions including the mouse $(-423$ to +68$)$, T. osimensis $(-429$ to $+55)$ or T. tokunoshimensis $(-429$ to +55$)$ promoter. The luciferase reporter construct containing each promoter 
Fig. 3. Comparison of the amino acid sequences and promoters of mouse and Tokudaia Sox3. A Amino acid sequences of mouse and T. osimensis SOX3. Identical residues are indicated by asterisks. The HMG-box is shaded in gray. The accession number of mouse SOX3 is NP_033263. B Promoter sequences of Sox3 in mouse, T. osimensis, and T. tokunoshimensis. All binding sites for transcription factors are framed. The $13 \mathrm{bp}$-deletion found in the 2 $\mathrm{X} 0 / \mathrm{X} 0$ Tokudaia species is shaded in gray. C Promoter sequences of Sox 3 in mouse, rat, and Tukadaia. The 13-bp deletion found in the $2 \mathrm{X} 0 / \mathrm{X} 0$ Tokudaia species is indicated by gray shading.

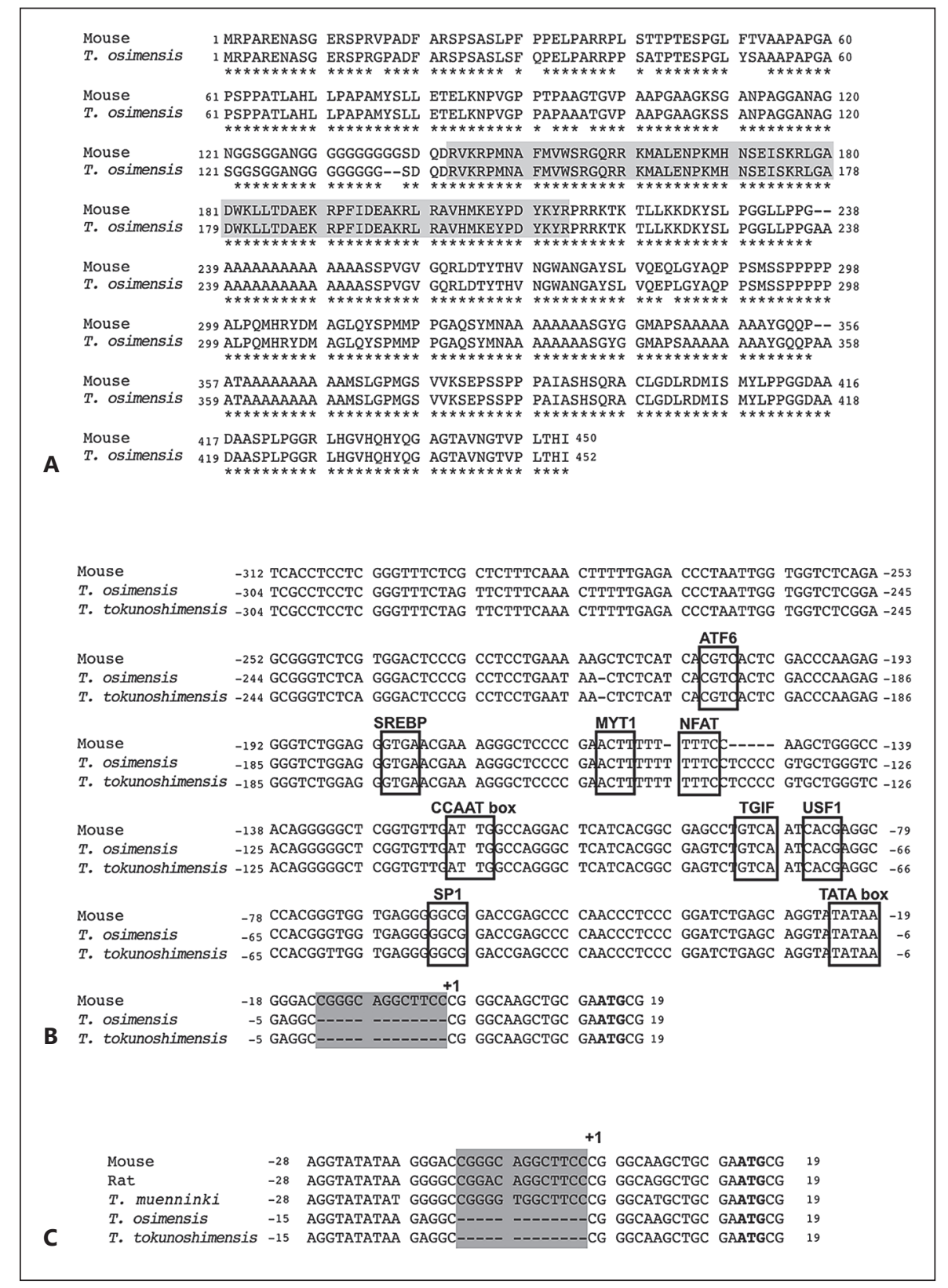

region was transfected into NT2/D1 cells. The mouse promoter showed a 63-fold increase in activity compared with the activity of the empty vector (Fig. 4). By contrast, the promoters of T. osimensis and T. tokunoshimensis showed a 26- and 27-fold increase in activity, respectively.

To examine the effect of the 13-bp deletion $(-1$ to -13$)$ found in the promoters of the 2 species of Tokudaia (gray shading in Fig. 3B, C) on Sox3 regulation, the promoter activity was measured using a construct in which the 13- bp deletion in the T. osimensis promoter was filled with the mouse sequence by overlap extension PCR. The filled T. osimensis promoter showed recovery of the activation, resulting in a 49 -fold increase in activity (Fig. 4).

\section{T. osimensis SOX3 Could Not Synergistically Activate TESCO}

To determine whether SOX 3 could regulate the Sox 9 expression instead of SRY in T. osimensis, we examined its transcriptional activity in a reporter gene assay using 


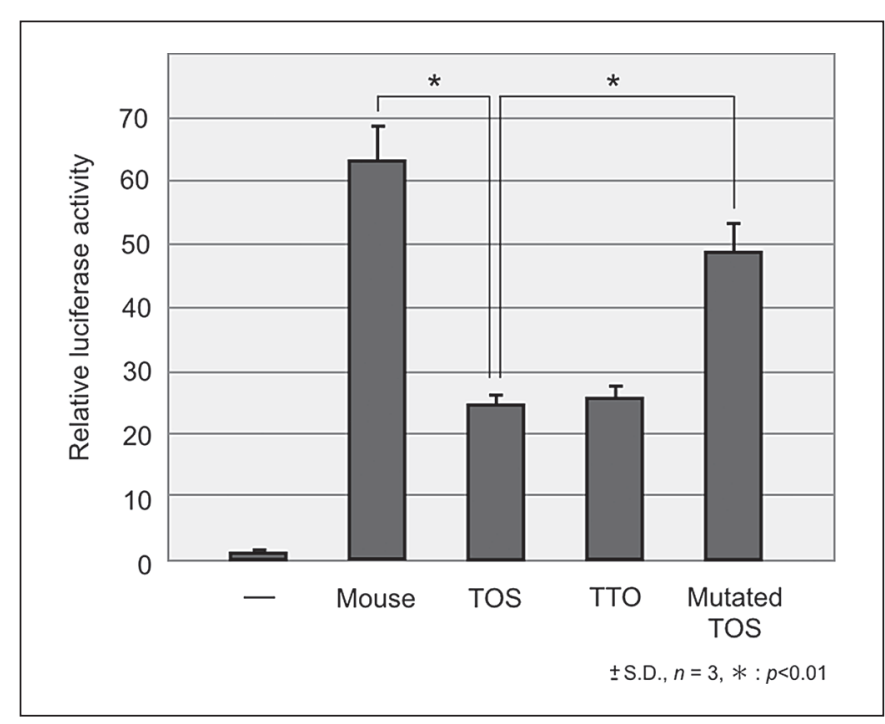

Fig. 4. Reporter gene assay in the Sox3 promoter. Comparison of the activities of the mouse, T. osimensis (TOS), and T. tokunoshimensis (TTO) Sox3 promoters, and a T. osimensis Sox3 promoter in which the 13-bp deletion was filled with the mouse sequence, in NT2/D1 cells. The fold-change in activity was calculated relative to the luciferase activity obtained from transfection with mouse promoter alone. Data are represented as mean \pm SD of at least 3 experiments. ${ }^{*} p<0.01$.

COS7 cells. mSF1 alone induced a greater than 6-fold increase in mouse TESCO activity compared with the activity observed when only empty expression vectors were added, whereas mouse TESCO was not significantly activated by mSRY or mSOX9 alone (dark gray bars in Fig. 5). Mouse TESCO showed a greater than 8 -fold increase in activity when it was co-expressed with a combination of mSF1 and mSRY or mSOX9, reflecting the synergistic regulation of Sox9 expression by SRY, SOX9, and SF1 [Sekido and Lovell-Badge, 2008]. Unlike mouse TESCO, T. osimensis TESCO did not show significant activity in response to the expression of $\mathrm{mSRY}$ and $\mathrm{mSOX} 9$ in combination with mSF1 (white bars in Fig. 5). This result was consistent with the findings of our previous study [Kimura et al., 2014].

Mouse and T. osimensis TESCO were not significantly activated by $\operatorname{mSOX} 3$ or T. osimensis SOX3 (SOX3) alone (Fig. 5). Co-transfection with a combination of mSF1 and mSOX 3 or SOX3 resulted in a greater than 2 -fold increase in activity of mouse and T. osimensis TESCO. This result is consistent with that of a previous study [Sutton et al., 2011]. However, this activity was lower than the activity observed when only mSF1 expression vector was added to mouse TESCO.

\section{Discussion}

The sequence of the Sox3 gene in T. osimensis shows a high degree of similarity with that of the mouse. Specially, the HMG-box, which is a DNA-binding domain that is important for the function of SOX3 as a transcription factor, is completely identical between the 2 species. Sox 3 was localized in a region of the $\mathrm{X}$ chromosome in T. osimensis homologous to mouse. Furthermore, the expression patterns of the Sox 3 gene in adult T. osimensis and mice (testis- and ovary-specific expression) were almost identical. These results indicate that the function of the Sox 3 gene reported in mice and humans is conserved in the Sry-lacking species, T. osimensis.

All of the putative binding sites for previously described transcription factors are conserved in the promoter regions of the 2 Tokudaia species. However, a 13bp deletion was found in the promoters of both X0/X0 Tokudaia species. Mouse, rat, and T. muenninki, which have a Y chromosome and the Sry gene, have no deletion (Fig. 3C). In the molecular phylogenetic tree previously reported by us, T. muenninki first diverged from the genus Tokudaia [Murata et al., 2010]. These results indicate that the deletion specifically occurred in the ancestral common species of the $2 \mathrm{X0} / \mathrm{X} 0$ Tokudaia species. To examine the effect of this deletion on Sox3 regulation, reporter gene assays were performed using the promoter sequences of mouse, both Tokudaia species with the deletion, and a mutated promoter in which the 13-bp deletion was filled with the mouse sequence. The Tokudaia promoters with the 13-bp deletion showed an approximately $60 \%$ decrease in activity compared with the activity of the mouse promoter. However, this decrease in activity was recovered by filling the deletion, resulting in an approximately $22 \%$ decrease in activity compared with the mouse sequence. These results suggest that the 13-bp deletion leads to a downregulation of Sox 3 expression in Tokudaia species. The functional consequence of this downregulation of Sox 3 expression was not evaluated in this study. However, the observed downregulation of Sox 3 does not support our hypothesis that the Sox 3 gene functions in sex determination instead of Sry. Therefore, we concluded that the Sox3 gene has no function in sex determination in Sry-lacking species of Tokudaia.

To determine whether Sox3 could regulate Sox9 expression instead of Sry in T. osimensis, reporter gene assays were performed using mouse and T. osimensis TESCO. T. osimensis SOX3 stimulated a greater than 2 -fold increase in mouse and T. osimensis TESCO activity in combination with $\mathrm{mSF} 1$, compared with the activity ob- 
Fig. 5. Reporter gene assay in TESCO. Comparison of the enhancer activities of mouse TESCO and Tokudaia osimensis TESCO in COS7 cells expressing a reporter construct and co-transfected with or without mSF1, mSRY, mSOX9, mSOX3, and T. muenninki SOX3. The fold-change in activity was calculated relative to the luciferase activity obtained from transfection with mouse TESCO or T. osimensis TESCO alone. Data are represented as mean \pm SD of at least 3 experiments. ${ }^{*} p<0.01$.

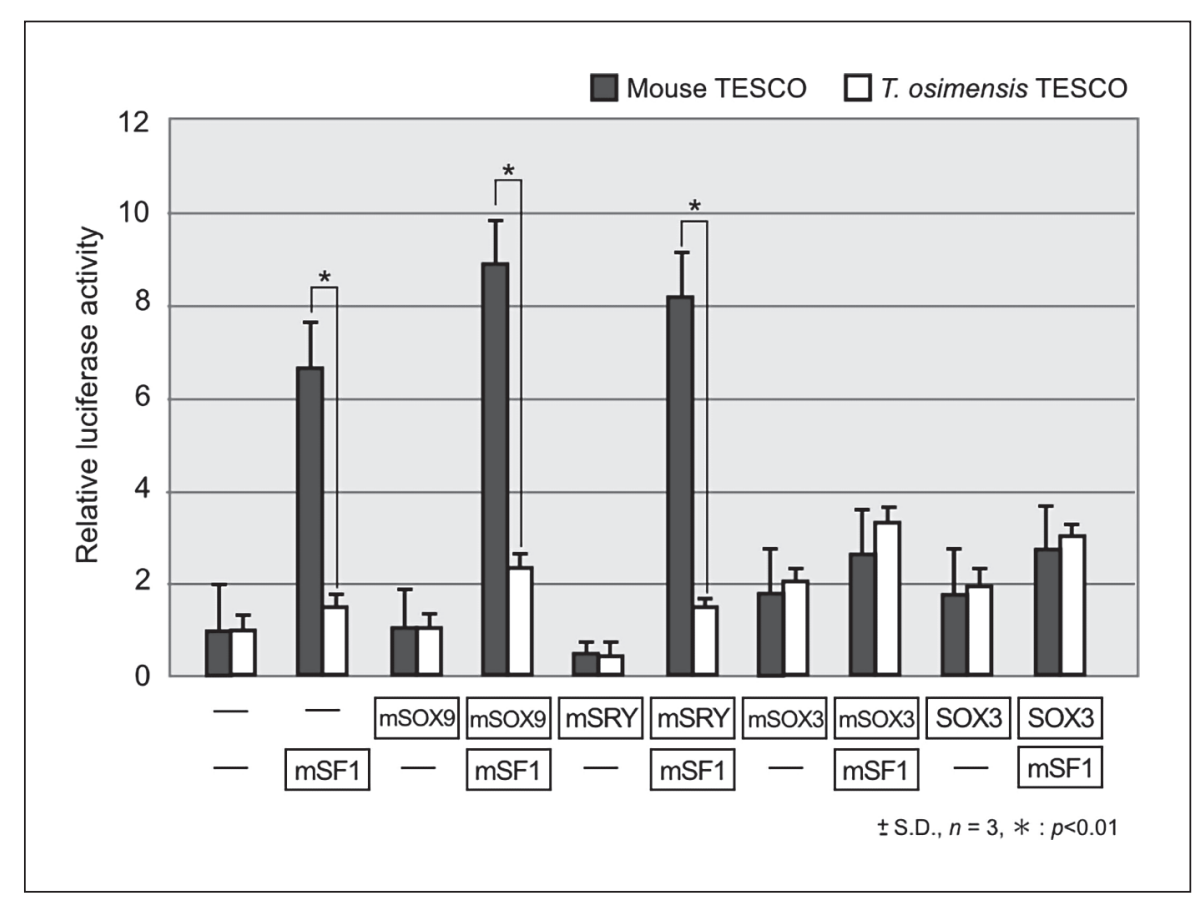

served when only the empty vector was added. A similar increase in activity was observed when $\mathrm{mSOX} 3$ and $\mathrm{mSF} 1$ were co-expressed. These results support the idea that the function of SOX3 as a transcription factor, as has been reported in mice and humans, is conserved in T. osimensis. The activity of T. osimensis TESCO induced by mSOX3 or T. osimensis SOX3 with mSF1 was lower than the activity observed when only mSF1 expression vector was added to mouse TESCO (Fig. 5). We could not determine the reason; however, physical interaction of SRY and SF1 proteins on the DNA-binding sites was indicated in a previous report [Sekido and Lovell-Badge, 2009]. An interaction of SOX3 and SF1 might suppress the SF1 activity to TESCO.

TESCO was first reported as a regulatory element that induces the expression of Sox 9 by binding SRY together with SF1 [Sekido and Lovell-Badge, 2008]. The TESCO sequence contains several SRY - and SF1-binding sites, which are highly conserved between mice, rats, dogs, and humans [Sekido and Lovell-Badge, 2008]. However, we previously found that there were nucleotide substitutions in 2 out of 3 SRY-binding sites and in 5 out of 6 SF1-binding sites in TESCO in all Tokudaia species [Kimura et al., 2014]. The activity was restored with a mutated version of TESCO in which the nucleotide substitutions found in the SRY- and SF1-binding sites were replaced with the mouse sequence. Although T. osimen- sis SOX3 could stimulate an approximately 2 -fold increase in T. osimensis TESCO activity with $\mathrm{mSF} 1$, this was a very low level compared to the level of synergistic regulation of Sox9 expression by SRY, SOX9, and SF1 in mouse. Therefore, we hypothesized that, if T. osimensis SOX3 has a role in sex determination, it regulates Sox 9 expression through an enhancer other than TESCO. A new enhancer for Sox9 regulation in the mouse, Enh13, a 557-bp element located $565 \mathrm{~kb}$ upstream of Sox9, has been recently reported [Gonen et al., 2018]. Enh13 is thought to be an early-acting enhancer; without it, Sox9 transcription fails to increase to a level at which other enhancers can act before the gene is silenced. Actually, several enhancer elements upstream of Sox 9 were found in mice and humans [Croft et al., 2018; Ogawa et al., 2018]. These findings indicate a redundancy in Sox 9 regulation that involves several enhancers. In T. osimensis, an enhancer other than TESCO might be important for sex determination independent of SRY. Further research to identify other candidate genes that replace Sry in sex determination is needed.

\section{Acknowledgement}

The authors thank Y. Sato for providing NT2/D1 cells, S. Sugawara, T. Otake, and R. Kimura for technical support, and C. Nishida for helpful suggestions in cell culture experiments. 


\section{Statement of Ethics}

All animal experiments described in this study were approved by the Institutional Animal Care and Use Committee of National University Corporation, Hokkaido University, and were performed in accordance with the Guidelines for the Care and Use of Laboratory Animals issued by Hokkaido University.

\section{Disclosure Statement}

The authors have no conflicts of interest to declare.

\section{Funding Sources}

This work was supported by JSPS KAKENHI Grant Number JP19H03267.

\section{Author Contributions}

K.W. and S.M. performed experiments and analyzed the data. T.J. performed sampling. A.K. conceived and designed the study and wrote the manuscript. All authors read and approved the final manuscript.

\section{References}

Bowles J, Schepers G, Koopman P: Phylogeny of the SOX family of developmental transcription factors based on sequence and structural indicators. Dev Biol 227:239-255 (2000).

Collignon J, Sockanathan S, Hacker A, CohenTannoudji M, Norris D, et al: A comparison of the properties of Sox-3 with Sry and two related genes, Sox-1 and Sox-2. Development 122:509-520 (1996)

Croft B, Ohnesorg T, Hewitt J, Bowles J, Quinn A, et al: Human sex reversal is caused by duplication or deletion of core enhancers upstream of SOX9. Nat Commun 9:5319 (2018).

Foster JW, Graves JA: An SRY-related sequence on the marsupial $\mathrm{X}$ chromosome: implications for the evolution of the mammalian testis-determining gene. Proc Natl Acad Sci USA 91:1927-1931 (1994)

-Gonen N, Futtner CR, Wood S, Garcia-Moreno SA, Salamone IM, et al: Sex reversal following deletion of a single distal enhancer of Sox9. Science 360:1469-1473 (2018).

Graves JA: Sex chromosome specialization and degeneration in mammals. Cell 124:901-914 (2006).

-Gubbay J, Collignon J, Koopman P, Capel B, Economou A, et al: A gene mapping to the sex-determining region of the mouse $\mathrm{Y}$ chromosome is a member of a novel family of embryonically expressed genes. Nature 346:245250 (1990)

- Ho SN, Hunt HD, Horton RM, Pullen JK, Pease LR: Site-directed mutagenesis by overlap extension using the polymerase chain reaction. Gene 77:51-59 (1989).

-Honda T, Suzuki H, Itoh M: An unusual sex chromosome constitution found in the Amami spinous country-rat, Tokudaia osimensis osimensis. Jpn J Genet 52:247-249 (1977).

-Honda T, Suzuki H, Itoh M, Hayashi K: Karyotypical differences of the Amami spinous country-rats, Tokudaia osimensis osimensis obtained from two neighbouring islands. Jpn J Genet 53:297-299 (1978).

-Josso N, Picard JY: Anti-müllerian hormone. Physiol Rev 66:1038-1090 (1986).

-Josso N, Cate RL, Picard JY, Vigier B, di Clemente $\mathrm{N}$, et al: Anti-müllerian hormone: the Jost factor. Recent Prog Horm Res 48:1-59 (1993).
Kamachi Y, Uchikawa M, Kondoh H: Pairing SOX off: with partners in the regulation of embryonic development. Trends Genet 16: 182-187 (2000).

Kimura R, Murata C, Kuroki Y, Kuroiwa A: Mutations in the testis-specific enhancer of SOX 9 in the $S R Y$ independent sex-determining mechanism in the genus Tokudaia. PLoS One 9:e108779 (2014).

Kobayashi T, Yamada F, Hashimoto T, Abe S, Matsuda Y, Kuroiwa A: Exceptional minute sexspecific region in the $\mathrm{X} 0$ mammal, Ryukyu spiny rat. Chromosome Res 15:175-187 (2007).

Kobayashi T, Yamada F, Hashimoto T, Abe S, Matsuda Y, Kuroiwa A: Centromere repositioning in the $\mathrm{X}$ chromosome of $\mathrm{XO} / \mathrm{XO}$ mammals, Ryukyu spiny rat. Chromosome Res 16:587-593 (2008).

Kovacevic Grujicic N, Mojsin M, Krstic A, Stevanovic M: Functional characterization of the human SOX3 promoter: identification of transcription factors implicated in basal promoter activity. Gene 344:287-297 (2005).

Kuroiwa A, Ishiguchi Y, Yamada F, Shintaro A, Matsuda Y: The process of a Y-loss event in an $\mathrm{XO} / \mathrm{XO}$ mammal, the Ryukyu spiny rat. Chromosoma 119:519-526 (2010).

Kuroiwa A, Handa S, Nishiyama C, Chiba E, Yamada F, et al: Additional copies of $C B X 2$ in the genomes of males of mammals lacking $S R Y$, the Amami spiny rat (Tokudaia osimensis) and the Tokunoshima spiny rat (Tokudaia tokunoshimensis). Chromosome Res 19:635644 (2011).

- Murata C, Yamada F, Kawauchi N, Matsuda Y, Kuroiwa A: Multiple copies of SRY on the large Y chromosome of the Okinawa spiny rat, Tokudaia muenninki. Chromosome Res 18:623-634 (2010).

-Murata C, Yamada F, Kawauchi N, Matsuda Y, Kuroiwa A: The Y chromosome of the Okinawa spiny rat, Tokudaia muenninki, was rescued through fusion with an autosome. Chromosome Res 20:111-125 (2012).

Ogawa Y, Terao M, Hara S, Tamano M, Okayasu $\mathrm{H}$, et al: Mapping of a responsible region for sex reversal upstream of Sox 9 by production of mice with serial deletion in a genomic locus. Sci Rep 8:17514 (2018).
Otake T, Kuroiwa A: Molecular mechanism of male differentiation is conserved in the SRYabsent mammal, Tokudaia osimensis. Sci Rep 9:32874 (2016)

Pask AJ, Harry JL, Renfree MB, Marshall Graves JA: Absence of SOX3 in the developing marsupial gonad is not consistent with a conserved role in mammalian sex determination. Genesis 27:145-152 (2000).

Pevny LH, Lovell-Badge R: Sox genes find their feet. Curr Opin Genet Dev 7:338-344 (1997).

Sekido R, Lovell-Badge R: Sex determination involves synergistic action of SRY and SF1 on a specific Sox9 enhancer. Nature 453:930-934 (2008).

Sekido R, Lovell-Badge R: Sex determination and SRY: down to a wink and a nudge? Trends Genet 25:19-29 (2009).

- Sinclair AH, Berta P, Palmer MS, Hawkins JR, Griffiths BL, et al: A gene from the human sex-determining region encodes a protein with homology to a conserved DNA-binding motif. Nature 346:240-244 (1990).

Stevanović M, Lovell-Badge R, Collignon J, Goodfellow PN: SOX3 is an X-linked gene related to SRY. Hum Mol Genet 2:2013-2018 (1993).

Sutou S, Mitsui Y, Tsuchiya K: Sex determination without the Y chromosome in two Japanese rodents Tokudaia osimensis osimensis and Tokudaia osimensis spp. Mamm Genome 12: 17-21 (2001).

Sutton E, Hughes J, White S, Sekido R, Tan J, et al: Identification of SOX3 as an XX male sex reversal gene in mice and humans. J Clin Invest 121:328-341 (2011)

Vigier B, Tran D, du Mesnil du Buisson F, Heyman Y, Josso N: Use of monoclonal antibody techniques to study the ontogeny of bovine anti-müllerian hormone. J Reprod Fertil 69: 207-214 (1983).

Wegner M: From head to toes: the multiple facets of Sox proteins. Nucleic Acids Res 27:14091420 (1999).

- Yamada F, Kawauchi F, Nakata K, Abe S, Kotaka $\mathrm{N}$, et al: Rediscovery after thirty years since the last capture of the critically endangered Okinawa spiny rat Tokudaia muenninki in the Northern part of Okinawa Island. Mamm Study 35:243-255 (2010). 